\title{
Caregiver burden in haemophilia: results from a single UK centre
}

By Kate Khair, Sylvia von Mackensen

Haemophilia caregivers face limitations in their life leading to perceived burden. This single-centre study investigates the impact of burden on caregivers' health-related quality of life (HRQoL).

Methods: Questionnaires for caregivers comprised demographic data, HRQoL (EQ-5D, SF-36) and caregiver burden (IOF: Impact on Family Scale). Children were also asked about their HRQoL (EQ-5D, Haemo-QoL Short Form).

Results: 20 consecutive parent/child dyads participated. $80 \%$ were mothers (mean age of $39.80 \pm 6.2$ years) with 1-3 haemophilic children aged $8-17$ years and $2.5 \pm 1.2$ children $<18$ years living in the household. Mothers did most childcare (80\%), 50\% worked part-time, and 55\% reported that haemophilia had an economic impact on their family. $80 \%$ of boys had haemophilia A; $60 \%$ were severely affected. Most received home treatment (85\%) and prophylaxis (80\%). Caregivers' and boys' HRQoL was similarly good (EQ-5D parents $M=0.90 \pm 0.1$ vs. $E Q-5 D_{\text {child }} M=0.81 \pm 0.3$ ); by contrast, boys reported better values in the EQ-VAS ( $M_{\text {child }}=90.25 \pm 10.0$ vs. $\left.M_{\text {parents }}=82.16 \pm 14.8\right)$. Caregivers reported highest impairments in the dimensions 'vitality' $(M=60.00 \pm 20.5)$ and 'emotional role' $(M=70.37 \pm 42.6)$ of the SF-36. In the IOF, caregivers reported highest impairments in the dimension 'negative impact' ( $M=60.08 \pm 20.7)$. Caregivers reporting high burden had significantly worse $\mathrm{HRQOL}$ in the domains 'bodily pain' $(p<.028)$ and 'social functioning' $(p<0.024)$ of the SF-36. Caregivers who reported that haemophilia had an economic impact on their family and those with a chronic disease showed

\section{KATE KHAIR}

Haemophilia Centre, Great Ormond Street Hospital for Children NHS Foundation Trust, London WC1N 3JH, UK. Email: Kate.khair@gosh.nhs.uk

SYLVIA VON MACKENSEN

Institute and Policlinics of Medical Psychology, University Medical Centre Hamburg-Eppendorf, Martinistrasse 52, 20246 Hamburg, Germany

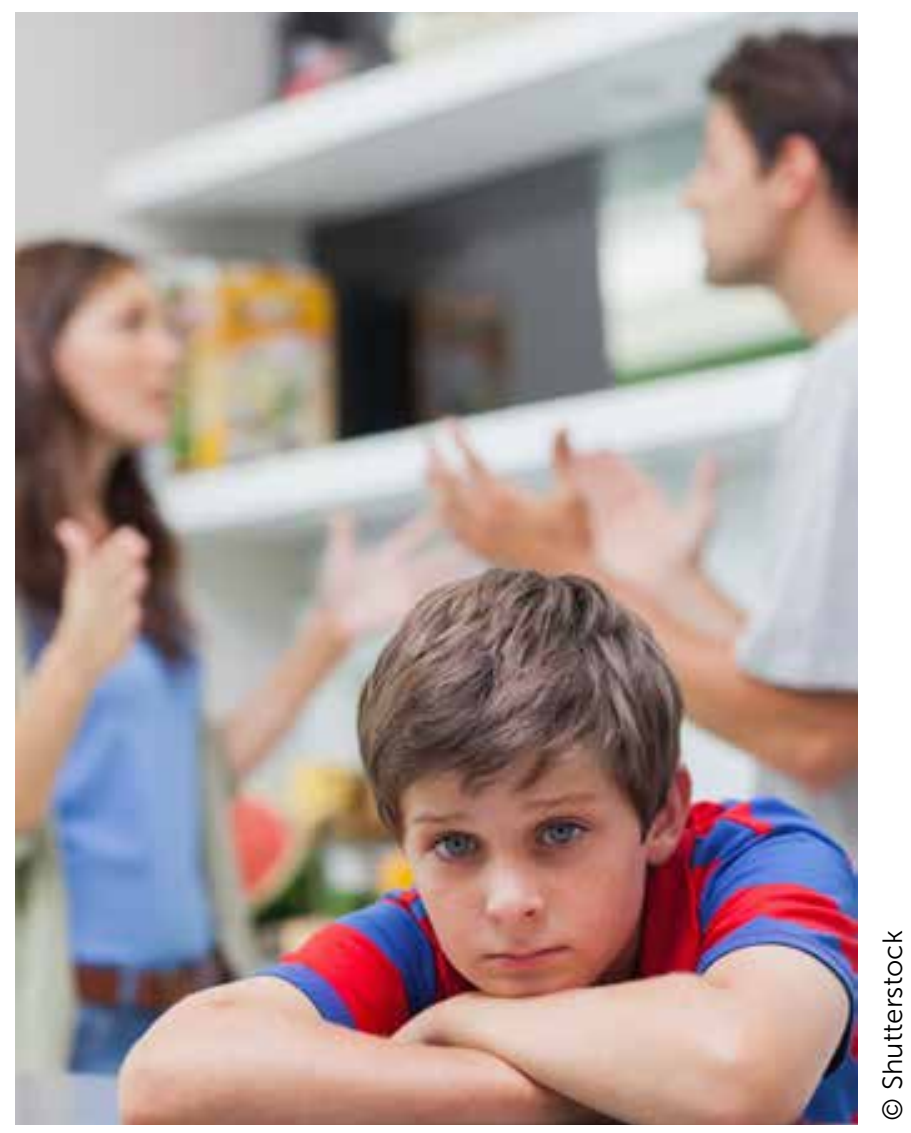

significant higher impairments in caregiver burden and their HRQoL.

Conclusions: The perceived burden of haemophilia has a direct impact on caregivers' HRQoL. Further studies with haemophilia-specific instruments are needed to verify these findings.

Keywords: haemophilia, caregiver burden, healthrelated quality of life, parents, IOF, EQ-5D, Haemo-QoL

n the United Kingdom (UK), there are 8,370

registered haemophilia patients, of which 1,982

are children and young people aged $<18$ years

${ }^{[1]}$. Haemophilia causes painful, spontaneous and trauma-related bleeding, predominantly in the weight- 
bearing joints, and can eventually result in joint degradation, pain and arthropathy ${ }^{[2]}$. The degree of bleeding correlates with the severity of the disease, defined by Biggs and Macfarlane as severe (factor levels of $<1 \mathrm{iu} / \mathrm{dl}$ ), moderate (levels $2-5 \mathrm{iu} / \mathrm{dl}$ ) and mild (5-50 iu/dl) ${ }^{[3]}$. Thus, those with severe haemophilia are most clinically affected.

The standard treatment of boys with severe haemophilia in the UK is prophylaxis. Treatment commences following the first bleeding episode, with the aim of establishing 'full' prophylaxis as soon as venous access allows ${ }^{[4]}$. For caregivers of children, this is an onerous time; they are learning about 'being' a parent of a child with haemophilia, as well as dealing with the complexities of learning medical skills and attending frequent hospital appointments ${ }^{[5,6,7,8]}$. This burden of disease management can lead to psychological (stress and coping, anxiety and depression, stigmatization and discrimination) as well as economic concerns ${ }^{[9,10,11]}$.

The impact of haemophilia on the quality of life (QoL) of affected individuals has been well documented in the literature and acknowledged in its treatment ${ }^{[12]}$. However, there remains a paucity of data about the impact of parenting a child with haemophilia on QoL of parents. It is expected that being a parent of a child with haemophilia will influence QoL, as they will worry and have fears related to the wellbeing of their child. Worries may include that something could happen to the child, future treatments and the long-term future.

As caregiver burden has been accepted by the UK National Institute of Clinical Excellence (NICE) as an outcome measure in other severe diseases, we aim to describe it for the first time as it relates to caregivers of children with haemophilia in the UK ${ }^{[13]}$. The rationale for this study was to describe caregiver burden and its determinants in parents of children with haemophilia, and how caregiver burden can affect health-related quality of life (HRQOL).

\section{METHODS}

The study is a single-centre non-interventional pilot study conducted between 2012-2013. Twenty caregivers of children, aged 8-17 years with haemophilia A or B of any severity, were included in the study. Consecutive parent/child dyads were recruited in a purposeful sampling manner.

A study questionnaire was compiled and completed by consecutive child/parent dyads attending routine clinical review. The study questionnaire comprised self-reported generic and disease-specific HRQoL questionnaires and a chronicgeneric instrument for the assessment of caregiver burden. In addition, children completed generic and disease-specific HRQoL questionnaires. Only one parent per child/parent dyad completed the study questionnaire, and did so independently. If the child needed help with the questionnaire, this was given by the study team.

Ethical approval to perform the study was granted by NRES Committee London - Surrey Borders and by the research and development team at Great Ormond Street Hospital/Institute of Child Health (reference number 12/LO/1415).

Parents and children completed a variety of validated instruments for the assessment of healthrelated quality of life (HRQOL) and caregiver burden.

Health-related quality of life (HRQoL): Parents completed the EQ-5D, a self-reported generic standardised instrument measuring health outcome ${ }^{[14]}$. It is applicable to a wide range of health conditions and treatments, and provides a simple descriptive profile and single index value for health status. It consists of five questions, each with three answer categories (1=no problem, 2=some problems, 3 =severe problems). The EQ-VAS is part of the EQ-5D, asking respondents to rate their overall health status on a standard vertical visual analogue scale (VAS) between 100 (best health imaginable) and 0 (worst health imaginable).

Parents also completed the SF-36 (version 1) ${ }^{[15,16]}$ The SF-36 is a multi-purpose, short-form health survey with 36 items. It yields an 8-scale profile of functional health and wellbeing scores ('physical functioning', 'role physical functioning', 'bodily pain', 'general health', 'vitality', 'social functioning', 'role emotional functioning' and 'mental health'), as well as psychometrically-based physical (PCS) and mental health (MCS) summary scores. Scores range from 0-100, with high values implying good HRQoL.

Children completed the EQ-5D-Youth (EQ-5D-Y), which is validated for use in children and young people aged 8-17 years, and the Haemo-QoL SF (Short Form), a disease-specific HRQoL questionnaire for children and adolescents with haemophilia aged 4-17 years (with 35 items for children aged 8-17 years) ${ }^{[17,18]}$. Answer categories were based on a 5 -point Likert scale, varying from $1=$ never to $5=$ always, with high values indicating a high impairment of HRQOL.

Caregiver burden: The Impact on Family Scale (IOF) 
Table 1: Sociodemographic characteristics of parents

\begin{tabular}{|c|c|c|c|}
\hline \multicolumn{2}{|l|}{ SOCIODEMOGRAPHIC CHARACTERISTICS } & N & \multirow{2}{*}{$\begin{array}{l}\text { PERCENTAGE } \\
80 \%\end{array}$} \\
\hline Who completed the questionnaire & Mother & 16 & \\
\hline & Father & 4 & $20 \%$ \\
\hline \multirow[t]{3}{*}{ Marital status } & Single & 1 & $5 \%$ \\
\hline & Married & 14 & $70 \%$ \\
\hline & Separated & 5 & $25 \%$ \\
\hline \multirow[t]{3}{*}{ Living situation } & With both parents & 10 & $50 \%$ \\
\hline & Only with mother & 9 & $45 \%$ \\
\hline & Only with father & 1 & $5 \%$ \\
\hline Chronic illness of caregiver & Yes & 3 & $15.8 \%$ \\
\hline Other chronic illness of child & Yes & 3 & $16.7 \%$ \\
\hline \multirow[t]{3}{*}{ Time working } & Full-time & 9 & $45 \%$ \\
\hline & Part-time & 10 & $50 \%$ \\
\hline & Not working & 1 & $5 \%$ \\
\hline Haemophilia causes economic impact on family & Yes & 11 & $55 \%$ \\
\hline Change of occupation due to haemophilia & Yes & 4 & $20 \%$ \\
\hline \multirow[t]{3}{*}{ Who mainly takes care of the child } & Mother & 16 & $80 \%$ \\
\hline & Father & 2 & $10 \%$ \\
\hline & Both & 2 & $10 \%$ \\
\hline & & $M \pm S D$ & MEDIAN (RANGE) \\
\hline \multicolumn{2}{|l|}{ Age mother } & $39.8 \pm 6.2$ & $40.5(28-52)$ \\
\hline \multicolumn{2}{|l|}{ Age father } & $44.22 \pm 7.4$ & $42.5(34-62)$ \\
\hline \multicolumn{2}{|l|}{ Age child } & $11.6 \pm 2.4$ & $11.5(8-17)$ \\
\hline \multicolumn{2}{|l|}{ Children living in the house } & $2.5 \pm 1.2$ & $2(1-6)$ \\
\hline \multicolumn{2}{|l|}{ Children with haemophilia living in the house } & $1.5 \pm 0.8$ & $1(1-3)$ \\
\hline
\end{tabular}

measures the impact of chronic childhood disease on the family ${ }^{[19,20]}$. The questionnaire consists of 27 questions (33 if the family has other children) pertaining to five domains ('financial support', 'social relationships', 'siblings', 'negative impact' and 'coping'). Subscales and the total score are transformed into a value of 0-100, with low values implying a high burden.

Additional information: Sociodemographic data were collected from caregivers, including age (child, parents), living situation, number of children with/without haemophilia, marital status, working and chronic illness of caregiver. Clinical data of children, including type and severity of haemophilia, inhibitor status, bleeding history, treatment regimen, were collected from the medical records.

Statistical analyses: The data were analysed using the IBM SPSS programme (version 23; SPSS Inc, Chicago, Illinois). Data are shown as a mean \pm standard deviation, median and range (minimum to maximum).
To measure the association between different PRO scales the Pearson Correlation coefficient $r$ was used with $r=1$ indicating a perfect positive correlation and $r=-1$ indicating a perfect negative correlation and $r=0$ no correlation at all. Differences concerning sociodemographic and clinical information (single parent, parent with a chronic disease, child with inhibitor, etc.) were tested using univariate ANOVA, Student's t-test or Chi-square tests, depending on the distribution of the data. High burden was defined based on the median split of the IOF total score (high burden $=1 \mathrm{OF}<67.29$ ) vs. low burden $=$ IOF $\geq 67.29$ ). A $p<0.05$ was considered statistically significant.

Multiple regression models using the enter method were analysed to assess the impact of children's and parents' characteristics on caregiver burden and HRQoL. Caregiver burden and HRQoL were dependent variables, while other variables (other illnesses of the child, working status, number of children with haemophilia, chronic illness of parents 
Table 2: Clinical data of haemophilic children

\begin{tabular}{|c|c|c|c|}
\hline \multicolumn{2}{|l|}{ CLINICAL DATA } & N & \multirow{2}{*}{$\begin{array}{l}\text { PERCENTAGE } \\
80 \%\end{array}$} \\
\hline Haemophilia type & $A$ & 16 & \\
\hline & $\mathrm{B}$ & 3 & $15 \%$ \\
\hline & B (Leyden) & 1 & $5 \%$ \\
\hline \multirow[t]{3}{*}{ Haemophilia severity } & Severe & 12 & $60 \%$ \\
\hline & Moderate & 4 & $20 \%$ \\
\hline & Mild & 4 & $20 \%$ \\
\hline \multirow[t]{2}{*}{ Treatment regimen } & On-demand & 4 & $20 \%$ \\
\hline & Prophylaxis & 16 & $80 \%$ \\
\hline \multirow[t]{3}{*}{ Type of prophylaxis $(n=16)$} & Primary & 9 & $56.3 \%$ \\
\hline & Secondary & 6 & $37.5 \%$ \\
\hline & Short-term & 1 & $6.2 \%$ \\
\hline \multirow[t]{5}{*}{ Prophylaxis frequency $(n=16)$} & Daily & 2 & $12.5 \%$ \\
\hline & $\begin{array}{l}\text { Five times/week } \\
\text { (pre-sport) }\end{array}$ & 2 & $12.5 \%$ \\
\hline & Alternate daily & 6 & $37.5 \%$ \\
\hline & Three times/week & 4 & $25 \%$ \\
\hline & Twice/week & 2 & $12.5 \%$ \\
\hline \multirow[t]{3}{*}{ Treatment administered } & Self & 9 & $45 \%$ \\
\hline & Family member & 9 & $45 \%$ \\
\hline & Hospital staff & 2 & $10 \%$ \\
\hline \multirow[t]{2}{*}{ Venous access } & Peripheral vein & 19 & $95 \%$ \\
\hline & Central line & 1 & $5 \%$ \\
\hline Home treatment & Yes & 17 & $85 \%$ \\
\hline \multirow[t]{2}{*}{ Inhibitor } & Ever & 5 & $25 \%$ \\
\hline & Current & 1 & $5 \%$ \\
\hline \multirow[t]{2}{*}{ Joint health } & Joint bleeds & 5 & $25 \%$ \\
\hline & Target joints & 1 & $5 \%$ \\
\hline \multirow[t]{4}{*}{ BMI } & Underweight & 5 & $25 \%$ \\
\hline & Normal weight & 11 & $55 \%$ \\
\hline & Overweight & 3 & $15 \%$ \\
\hline & Obese & 1 & $5 \%$ \\
\hline & & $\mathrm{M} \pm \mathrm{SD}$ & MEDIAN (RANGE) \\
\hline \multicolumn{2}{|l|}{ No. of total bleeds in past 3 months } & $0.3 \pm 0.6$ & $0(0-2)$ \\
\hline \multicolumn{2}{|l|}{ No. of joint bleeds in past 3 months } & $1.25 \pm 0.5$ & $1(1-2)$ \\
\hline \multicolumn{2}{|l|}{ No. of muscle bleeds in past 3 months } & 0 & 0 \\
\hline \multicolumn{2}{|l|}{ No. of other bleeds in past 3 months } & 1 & $1(1-1)$ \\
\hline
\end{tabular}

and economic impact of haemophilia on the family) were taken as predictors.

\section{RESULTS}

Sociodemographic characteristics of caregivers From the participating twenty caregivers, $80 \%$ were mothers with a mean age of $39.8 \pm 6.2$ years; fathers had a mean age of $44.22 \pm 7.4$ years. Most caregivers were caring for a child between 8-12 years. In one family, the mother was not living with the child. Most caregivers were married (70\%). Three caregivers had a chronic illness (hypertension, hypothyroidism, long-term survivor of childhood acute lymphoblastic leukaemia (ALL) and three children had a second chronic illness (ADHD, autism, hypermobility). Almost all caregivers were working part- or full-time (95\%); $50 \%$ of those working part-time/not working were doing so because they were caring for their haemophilic child. The 
Table 3: Correlation of the Impact on Family (IOF) scale with HRQoL of caregivers and haemophilic children

\begin{tabular}{|c|c|c|c|c|c|c|c|c|}
\hline SUBJECTS & $\begin{array}{l}\text { QUESTION- } \\
\text { NAIRE }\end{array}$ & DIMENSIONS & $\begin{array}{l}\text { FINANCIAL } \\
\text { SUPPORT } \\
r:\end{array}$ & $\begin{array}{l}\text { SOCIAL } \\
\text { RELATIONS } \\
\text { PEARSON CO }\end{array}$ & $\begin{array}{l}\text { SIBLING } \\
\text { RELATION }\end{array}$ & $\begin{array}{l}\text { NEGATIVE } \\
\text { IMPACT } \\
\text { JEFFICIENT }\end{array}$ & COPING & IOF \\
\hline \multirow[t]{12}{*}{ Parents } & \multirow[t]{10}{*}{ SF-36 } & $\begin{array}{l}\text { Physical } \\
\text { functioning }\end{array}$ & - & .553 & .457 & - & - & .559 \\
\hline & & $\begin{array}{l}\text { Role physical } \\
\text { functioning }\end{array}$ & .674 & .676 & .539 & - & - & .675 \\
\hline & & Bodily pain & .538 & .549 & - & - & - & .550 \\
\hline & & $\begin{array}{l}\text { General } \\
\text { health }\end{array}$ & .550 & .713 & .589 & - & - & .616 \\
\hline & & Vitality & - & .491 & .466 & - & - & .475 \\
\hline & & $\begin{array}{l}\text { Social } \\
\text { functioning }\end{array}$ & .704 & .651 & .600 & - & - & .661 \\
\hline & & $\begin{array}{l}\text { Role } \\
\text { emotional } \\
\text { functioning }\end{array}$ & .498 & - & - & - & - & - \\
\hline & & Mental health & .561 & .508 & .485 & - & - & .540 \\
\hline & & PCS & - & - & - & - & - & - \\
\hline & & MCS & .537 & .484 & .484 & - & - & .520 \\
\hline & \multirow[t]{2}{*}{$E Q-5 D$} & $E Q-5 D$ & .502 & - & - & - & - & - \\
\hline & & EQ-VAS & .646 & .533 & .538 & - & .465 & .555 \\
\hline \multirow[t]{3}{*}{ Children } & Haemo-QoL & $\begin{array}{l}\text { Haemo-QoL } \\
\text { SF }\end{array}$ & - & - & -.496 & - & - & - \\
\hline & \multirow[t]{2}{*}{$E Q-5 D$} & $E Q-5 D-Y$ & - & - & .494 & - & - & - \\
\hline & & EQ-VAS & - & - & - & - & - & - \\
\hline
\end{tabular}

IOF: Total Score of Impact of Family Scale; SF-36: generic Short Form Health Survey 36; Haemo-QoL SF: Short Form haemophilia-specific HRQoL questionnaire; EQ-5D: generic health outcome measure

majority reported that haemophilia causes an economic impact on the family (55\%).

All children had siblings with whom they resided; the mean number of children below 18 years living in each household was $2.5 \pm 1.2$ (range 1-6), with $1.5 \pm 0.8$ (range 1-3) of these also having haemophilia (Table 1).

\section{Clinical data of children}

The mean age of boys in the study was $11.6 \pm 2.4$ years (range 8-17 years). The majority had haemophilia A $(80 \%)$, were severely affected $(60 \%)$, and treated prophylactically $(80 \%)$. One boy with haemophilia B Leyden was included and was considered as 'mild' at the time of the study. 9 boys were on primary prophylaxis, 17 were on home treatment $(85 \%)$ and 9 usually self-infused (45\%). Five boys had had an inhibitor; one was still on daily immune tolerance and had a port-a-cath in situ (Table 2).

HRQoL

Caregivers reported, in general, a good HRQoL, showing highest impairments in the dimensions 'vitality' $(M=60.0 \pm 20.5)$ and 'emotional role' $(M=70.37 \pm 42.6)$ of the generic SF-36. Caregivers reported good HRQoL on the generic $E Q-V A S(M=82.16 \pm 14.8)$ and on the $E Q-5 D$ $(M=0.90 \pm 0.1)$.

Children reported good $\mathrm{HRQ}$ oL on the generic EQVAS $(M=90.25 \pm 10.1)$ and on the EQ-5D $(M=0.81 \pm 0.3)$. They reported in the haemophilia-specific HaemoQoL SF highest impairments in the dimensions 'physical health' $(M=31.35 \pm 25.9)$ and 'treatment' ( $M=27.96 \pm 26.6)$.

No difference was found between the EQ$5 D$ of caregivers and the EQ-5D-Y of children. By contrast boys reported better values in the EQ-VAS ( $M_{\text {child }}=90.25 \pm 10.0$ vs. $\left.M_{\text {parents }}=82.16 \pm 14.8\right)$.

\section{Impact of burden}

Caregivers showed highest burden related to the disease of their sons in the dimension 'negative impact' of the IOF scales ( $M=60.08 \pm 20.7)$. Primarily, they "worried about what will happen to their child in the 


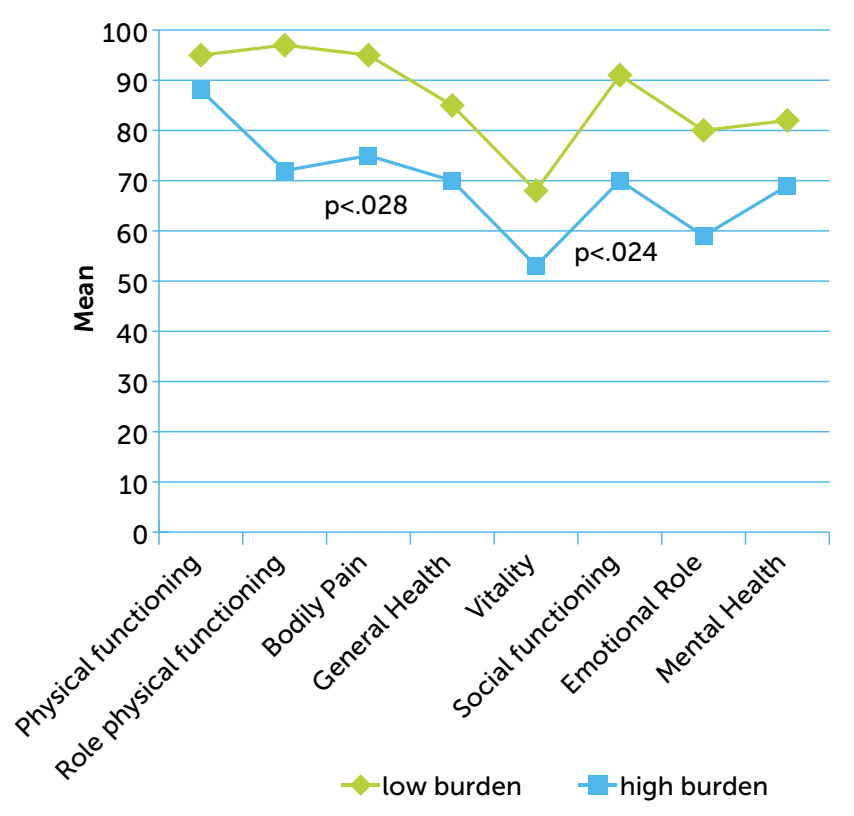

High values imply good HRQoL;

Tested for significance using the Student's T-Test

Figure 1: Difference in HRQoL (SF-36) between caregivers with a high and low reported burden (IOF)

future" (65\%), "were thinking about not having more children because of the illness" (44.4\%), and "were wondering sometimes whether their child should be treated 'differently' or the same as a normal child" (35\%).

Moderate-to-strong correlation was found between the IOF scales and caregivers' HRQOL (SF-36, EQ-VAS). No correlation was found between the IOF and the EQVAS of the children; only one moderate correlation was found between the subscale 'sibling' of the IOF and the total score of the Haemo-QoL short form (Table 3).

Caregivers who reported a high burden on the IOF (<67.29) had significantly worse HRQoL in the domains 'bodily pain' ( $p<0.028)$ and 'social functioning' $(p<0.024)$ of the SF-36 (see Figure 1) and in the EQ-VAS ( $M_{\text {high }}$ burden $=74.78 \pm 16.1$ vs. Mlow burden $=88.88 \pm 10.1$ ) $(p<0.034)$; no difference was found on the EQ-5D.

\section{Differences in impact of burden and HRQoL of caregivers}

The greatest impact on perceived caregiver burden and HRQoL was found where caregivers reported that haemophilia causes an economic impact on their family. Significant differences were found in the domains 'financial support' $(p<0.008)$, 'social relations' $(p<0.042)$ and in the total score of the IOF $(p<0.033)$ (see Figure $2)$, and in the domains 'social functioning' ( $p<0.002)$, 'role emotional functioning' ( $p<0.043)$, 'mental health' $(p<0.009)$ and the MCS $(p<0.027)$ of the SF-36.

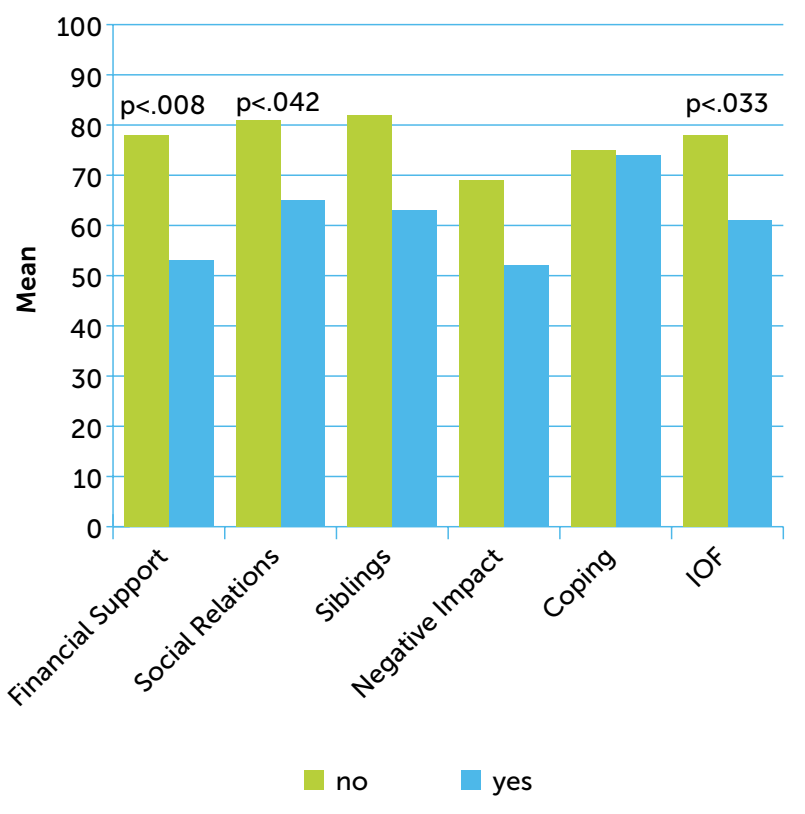

Low values imply high burden;

Tested for significance using the Student's T-Test

Figure 2: Difference in caregiver burden (IOF) between caregivers reporting an economic impact on their family and those without economic impact

Caregivers who had a chronic disease reported higher impairments in their HRQoL; significant differences were found in the domains 'physical functioning' ( $p<0.007)$, 'bodily pain' ( $p<0.025)$ and the PCS $(p<0.049)$ of the SF36 and in the EQ-5D ( $p<0.011)$ using the Mann-Whitney $U$-Test (data not presented here).

Further significant differences were found in caregiver HRQoL related to the clinical situation of their child. Caregivers of children with severe haemophilia reported higher impairments in their 'role emotional functioning' of the SF-36 $(p<.043)$ and caregivers of children treated prophylactically had a significant better EQ-VAS ( $p<.023)$.

There were also significant differences concerning caregivers' characteristics. Caregivers who changed their occupation due to caring for a child with haemophilia reported higher impairments (Myes $=51.39 \pm 17.2$ vs. $M_{n o}=76.11 \pm 20.2$ ) in the domain 'siblings' of the IOF $(p<0.040)$. Caregivers with more than one child with haemophilia under 18 years living in the house reported a better 'role emotional functioning' $(p<0.020)$ and MCS $(p<0.025)$ in the SF-36 than parents with only one child with haemophilia. When two caregivers were taking care of the child, they reported a better PCS in the SF-36 (Mone $=52.87 \pm 6.4$ vs. $\left.M_{\text {two }}=58.62 \pm 4.2\right)(p<0.039)$.

No difference was found for age of caregiver, marital status, number of children under 18 years living in the house, working status, number of total bleeds, inhibitors or having children with another chronic disease. 
Table 4: Multiple linear regression models to predict caregiver burden (IOF) and HRQoL (MCS, EQ-5D)

\begin{tabular}{|c|c|c|c|c|c|c|}
\hline \multirow[b]{2}{*}{ PREDICTORS } & \multicolumn{2}{|c|}{ IOF } & \multicolumn{2}{|c|}{ MCS } & \multicolumn{2}{|c|}{$E Q-5 D$} \\
\hline & BETA & $\mathbf{P}$ & BETA & $\mathbf{P}$ & BETA & $\mathbf{P}$ \\
\hline Working status & .561 & .029 & .173 & - & .544 & .038 \\
\hline Child has other chronic disease & .231 & - & .448 & - & .232 & - \\
\hline $\begin{array}{l}\text { No of children }<18 \text { years with } \\
\text { haemophilia in house }\end{array}$ & .322 & - & .437 & .082 & .261 & - \\
\hline Parents have chronic disease & .440 & .061 & -.174 & - & .483 & .050 \\
\hline $\begin{array}{l}\text { Haemophilia economic impact } \\
\text { on family }\end{array}$ & .491 & .040 & .532 & .039 & .425 & .078 \\
\hline R2 & \multicolumn{2}{|c|}{$57.4 \%$} & \multicolumn{2}{|c|}{$56.9 \%$} & \multicolumn{2}{|c|}{$54.3 \%$} \\
\hline
\end{tabular}

IOF: total score of Impact on Family scale

EQ-5D: generic health outcome measure

MCS: Mental Component Score of the generic SF-36 HRQoL questionnaire

$R^{2}$ : value explains how much variance in the analysis is explained by predictor variables

'Working status' and 'economic impact of haemophilia on family' could explain $57.4 \%$ of the variance in the value of caregiver burden (IOF) $(F(5,11)$ $=2.967, \mathrm{p}<0.062$ ). 'Having a child with other chronic illness', 'number of children with haemophilia under 18 years living in the house' and 'caregiver with chronic disease' did not significantly predict caregiver burden (Table 4). The same predictors were used to explain the variance of caregivers' HRQoL; $56.9 \%$ of the variance of MCS and $54.3 \%$ of the variance of EQ-5D could be explained (Table 4).

\section{Discussion}

This is the first study examining caregiver burden in haemophilia in the UK. In this single centre, caregivers reported the highest burden in the dimension 'negative impact' of the generic IOF. High burden had an impact on caregivers' HRQoL. Caregiver burden was mainly affected by the perceived economic impact on the family or chronic disease of the caregiver. 'Working status' and 'economic impact of haemophilia on family' were significant predictors of caregiver burden.

In a meta-analysis of parental experience of caring for a child with long-term conditions, parents became physically and emotionally overburdened, which manifested as 'chronic fatigue, frustration and feeling emotionally challenged' [21]. By contrast, in our study caregivers were predominantly healthy, with only few reporting chronic illness.

Murphy et al. state that physical and emotional health was negatively impacted by the demands of care-giving, with caregivers describing chronic physical and emotional ailments directly attributable to care-giving. These were most evident amongst mothers, who were most often primary caregivers [22] In our study, mothers were also predominantly the main caregivers; six were single parents. Weidebusch et al. reported that parents experienced a higher burden due to their child's haemophilia if they were without partner support ${ }^{[10]}$. Single mothers have significantly higher levels of vulnerability than married mothers, associated with reduced income and physical and mental health problems, which could not be confirmed in our study ${ }^{[23]}$.

It is difficult for mothers to seek or return to employment due to the demands of haemophilia care ${ }^{[6]}$. $50 \%$ of caregivers in our study who worked part-time did so due to their child's haemophilia. Shahly et al. reported that caring for those with chronic illness increasingly falls on family caregivers who are vulnerable to the burden of financial strain, with uncompensated family care-giving being an important societal asset that offsets rising formal healthcare costs ${ }^{[24]}$. In our study, $55 \%$ of parents reported a negative economic impact caused by haemophilia. Dekoven et al. found that 'financial' aspects and 'emotional stress', among other issues, are burdensome for caregivers of haemophilic children, which was confirmed in our study ${ }^{[25]}$.

Caregiver burden was demonstrated in concerns about the future, both in terms of what might happen to caregivers' current and future children. This aspect has been identified by others ${ }^{[28,10]}$. Supportive care should be introduced to help parents cope with caring to reduce parental stress, anxiety and burden, which may in turn improve HRQoL of both the caregiver and child. The impact of having a child with haemophilia on HRQoL in our study was only seen in the 'emotional role' dimension of the SF-36. 
This is a small single-centre study; our findings may not be reproducible and may be affected by the culture of the haemophilia centre, including how children are treated and parents are supported. A multi-centre, international study is planned using a newly developed haemophilia-specific instrument assessing caregiver burden ${ }^{[26]}$.

\section{Conclusion}

Caregivers of children with haemophilia reported generally good health and QoL, but having a child with haemophilia caused additional burden for some. Routine haemophilia care should include psychological assessment and support for caregivers, which should be evaluated using outcome measures quantifying both HRQOL and caregiver burden.

\section{Author contributions}

SVM and KK designed the study and wrote the paper. $\mathrm{KK}$ recruited the child/caregiver dyads. SvM analysed the data.

\section{Disclosures}

$\mathrm{KK}$ and SvM received an unrestricted educational grant for the conduct of the study by Baxalta.

This is an Open Access article distributed under the terms of the Creative Commons Attribution License (http://creativecommons.org/licenses/by/2.0), which permits unrestricted use, distribution, and reproduction in any medium, provided the original work is properly cited.

\section{Acknowledgements}

We would like to thank the parents who participated in this study for donating their time so willingly.

\section{REFERENCES}

1. 2015 National Haemophilia Database Annual Returns for 2014. Available at www.ukhcdo.org last accessed 10th April 2016

2. Valentino LA. Blood-induced joint disease: the pathophysiology of hemophilia arthropathy. J Thomb Haemost 2010; 8: 1895- 902.

3. Biggs R, MacFarlane RG. Haemophilia and the related conditions: a survey of 187 cases. Br J Haematol 1958; 4: 1-27.

4. Richards M, Williams M, Chalmers E, et al.; Paediatric Working Party of the United Kingdom Haemophilia Doctors' Organisation. A United Kingdom Haemophilia Centre Doctors Organization guideline approved by the British Committee for Standards in Haematology: guideline on the use of prophylactic factor VIII concentrate in children and adults with severe haemophilia A. Br J Haematol. 2010; 149(4): 498-507.

5. Vidler $\mathrm{V}$. Teaching parents advanced clinical skills. Haemophilia. 1999; 5(5): 349-53.
6. Beeton K, Neal D, Watson T, Lee CA. Parents of children with haemophilia - a transforming experience. Haemophilia. 2007; 13(5): $570-9$.

7. Myrin Westesson L, Sparud-Lundin C, Wallengren C, Baghaei F. A tortuous route to a capable fatherhood: the experience of being a father to a child with severe haemophilia. Haemophilia. 2015; 21(6): 799-805.

8. Myrin-Westesson L, Baghaei F, Friberg F. The experience of being a female carrier of haemophilia and the mother of a haemophilic child. Haemophilia. 2013; 19(2): 219-24.

9. Torres-Ortuno A, Cuesta-Barriuso R, Nieto-Munuera J. Parents of children with haemophilia at an early age: assessment of perceived stress and family functioning. Haemophilia 2014; 20: 756-62

10. Weidebusch S, Pollman H, Siegmund B, Muthny F. Quality of life, psychosocial strains and coping in parents of children with haemophilia. Haemophilia 2008; 14(5): 1014-22.

11. Von Mackensen S, Gringeri A. Quality of life in haemophilia. In: Preedy VR, Watson RR (eds). Handbook of Disease Burdens and Quality of Life Measures. Heidelberg: Springer; 2009. Vol 3. Chapter 12, 1895-920.

12. Von Mackensen S, Gringeri A. Quality of life in hemophilia. In: Lee CA, Berntop EE, Hoots WK (eds). Textbook of Hemophilia, 3rd edn. Oxford: Wiley Blackwell Publishing Ltd; 2014, 478-88.

13. Department of Health. Equity and excellence: liberating the NHS. London: HMSO; 2010. Available from https://www.gov. uk/government/uploads/system/uploads/attachment_data/ file/213823/dh_117794.pdf (accessed 15 December 2016).

14. Szende A, Oppe M, Devlin N (eds). EQ-5D Value Sets: Inventory, Comparative Review and User Guide. Doordrecht: Springer; 2010.

15. Ware J Jr, Kosinski M, Keller SD. SF-36 Physical and Mental Health Summary Scales: A User's Manual. Boston, Massachussetts: The Health Institute, 1994.

16. Ware JE Jr, Sherbourne CD. The MOS 36-item short-form health survey (SF-36). I. Conceptual framework and item selection. Med Care 1992; 30: 473-83.

17. Ravens-Sieberer U, Wille N, Badia X, et al. Feasibility, reliability, and validity of the EQ-5D-Y: results from a multinational study. Qual Life Res 2010; 19(6): 875-86.

18. Von Mackensen S, Bullinger M for The Haemo-Qol Group. Development and testing of an instrument to assess the quality of life of children with haemophilia in Europe. Haemophilia 2004, 10 (Suppl. 1): 17-25.

19. Stein RE, Riessman CK The development of an impact-on-family scale: preliminary findings. Med Care. 1980; 18(4): 465-72.

20. Ravens-Sieberer U, Morfeld M, Stein RE, et al. [The testing and validation of the German version of the impact on family scale in families with children with disabilities] [Article in German]. Psychother Psychosom Med Psychol 2001; 51(9-10): 384-93.

21. Smith S, Cheater F, Bekker H. Parents' experiences of living with a child with a long-term condition: a rapid structured review of the literature. Health Expect 2015; 18(4): 452-74.

22. Murphy NA, Christian B, Caplin DA, Young P. The health of caregivers for children with disabilities: caregiver perspectives. Child Care Health Dev. 2007; 33(2): 180-7.

23. Mullins LL, Wolfe-Christiansen C, Chaney JM, et al. The relationship between single-parent status and parenting capacities in mothers of youth with chronic health conditions: the mediating role of income. J Pediatr Psychol 2011; 36(3): 249-57. 
24. Shahly V, Chatterji S, Gruber MJ, et al. Cross-national differences in the prevalence and correlates of burden among older family caregivers in the World Health Organization World Mental Health (WMH) Surveys. Psychol Med 2013; 43(4): 865-79.

25. DeKoven $M$, Karkare $S$, Kelley LA, et al. Understanding the experience of caring for children with haemophilia: crosssectional study of caregivers in the United States. Haemophilia 2014; 20(4): 541-9.
26. Von Mackensen S, Wisniewski T, Urgo JC, Boggio L. Pilot test of the first hemophilia-specific burden scale for caregivers of children with hemophilia in the United States-the HEMOphilia associated CAregiver Burden scale (HEMOCAB ${ }^{\mathrm{TM}}$ ). Journal of Thrombosis and Haemostasis 2015; 13 (Suppl. 2): PO256.

\section{The Journal of Haemophilia Practice}

\section{An open-access journal for sharing experience in the care of people with bleeding disorders}

\section{www.haemjournal.com}

